\title{
Monseñor Romero y la izquierda armada salvadoreña
}

Está próximo a cumplirse el veinte aniversario del asesinato de Monseñor Oscar Arnulfo Romero. La ocasión es propicia para volver la vista hacia uno de los aspectos que, aún ahora, sigue despertando recelos - surgidos de una lectura simplista de la realidad - en quienes no quieren o no pueden entender la función que desempeñó Monseñor Romero en esas difíciles coyunturas que marcaron a El Salvador la década de los años setenta y principios de la década de los años ochenta: su relación con las organizaciones político militares.

Para quienes vieron en su momento a Monseñor Romero como un enemigo, el asunto es claro: él fue, al igual que los grupos guerrilleros, un agente de la subversión, es decir, alguien que utilizó el púlpito para socavar el orden establecido. En una hoja volante se caracteriza una misa de Monseñor Romero - celebrada en la Iglesia María Auxiladora, el 19 de julio de 1977- como una "misa-mitin" y, además, se califica al Arzobispo como "agitador profesional" que hace el "cachete a las organizaciones marxistas". Todavía hay quienes piensan así; todavía hay quienes aceptan, sin el menor ánimo crítico, esta imagen equivocada - fraguada por los sectores más duros de la derecha salvadoreña en los años setenta y ochenta- de Monseñor Romero.

Como contrapartida están los que ven a Monseñor Romero como un hombre ingenuo y de buena fe, a quien se forzó (por las vías del engaño y la manipulación) a que hiciera cosas y apoyara causas ajenas a su quehacer de pastor. Monseñor Romero era bueno - dicen-, pero tuvo malas influencias (entre otras las de los jesuitas), las cuales se valieron de su humildad y debilidad de carácter. Por tanto, de lo que se trata ahora es de rescatar a ese Monseñor Romero espiritual; es ese Monseñor Romero el que debe ser canonizado.

Por último, están aquellos que ven al Arzobispo asesinado como un hombre con ideas claras, unívocas, que siempre sabía a qué atenerse o qué decisión tomar. Para éstos, Monseñor Romero es una especie de superhombre, incapaz de titubear o dudar: sus decisiones y opciones las tomó a partir de valoraciones frías y diáfanas de la realidad. Coherencia, frialdad, claridad y determinación: ¿no son estas acaso virtudes que sólo los santos o los seres humanos extraordinarios pueden tener?

Pese al arraigo de esas visiones de Monseñor Romero, las tres, cada una a su modo, falsean lo que fue su presencia en la realidad histórica salvadoreña. Comencemos con la última de ellas. Esta olvida una cosa importante: que Monseñor Romero fue un ser humano, extraordinario sí, pero no por no equivocarse o no dudar, sino porque en medio de dudas, equivocaciones y rectificaciones pudo medirle el pulso al país en aquellos años aciagos y tomar decisiones difíciles para él y para la Iglesia. Su Diario personal' no deja dudas al respecto: Monseñor Romero no siempre tuvo claridad plena acer-

1. Mons. Oscar A. Romero, Su diario, San Salvador, Arzobispado de San Salvador, 1999. 
ca de lo que pasaba en el país o acerca de cuál era la mejor forma de responder ante la distintas coyunturas - sangrientas muchas de ellas- que se presentaban.

Esto nos lleva a la segunda perspectiva: la que insiste en la dimensión espiritual de Monseñor Romero. Según esta lectura, el bueno de Monseñor Romero fue manipulado, dada su debilidad de carácter, por quienes querían imponer sus propios intereses al país y a la Iglesia. Para quienes ven así las cosas, Monseñor Romero era un ser dócil y sin carácter, que hizo lo que hizo por influencia de otros. Pues bien, ni su Diario, sus Cartas pastorales y Homilías ni la experiencia que tuvieron con él distintas personas avalan esta visión tan simplista de su figura. Sin dejar de tener altibajos psicosomáticos - iquién, incluso, con menos presiones no los tiene?-, Monseñor Romero fue, en momentos cruciales, una personalidad de carácter, capaz de asumir con determinación, tras haber reflexionado detenidamente, decisiones difíciles y peligrosas. Un ser dócil y sin carácter no hubiera enfrentado a los militares y a los grupos de poder económico, habida cuenta de los mecanismos de seducción y chantaje de los que estos quisieron valerse para sumarlo a sus filas o, al menos, para que dejara de ser tan molesto.

Asimismo, sin dejar de escuchar a otros -militares, empresarios, profesionales, políticos, miembros de organizaciones populares, guerrilleros-, Monseñor Romero, tras consultarlo consigo mismo, decidió hacer o decir, por su cuenta y riesgo, lo que a él le parecía correcto. Aquí su Diario personal - -ese conjunto de reflexiones cotidianas y pláticas consigo mismo y con Dios que Monseñor Romero hizo desde el 31 de marzo de 1978 hasta el 20 de marzo de 1980 - es crucial para entender las encrucijadas en las que se vio envuelto, así como el modo en que fraguó muchas de sus decisiones.

Finalmente, llegamos al primero de los puntos: el que se refiere a la relación de Monseñor Romero con la izquierda armada. La óptica que hemos expuesto antes - la que identifica a Monseñor Romero con los grupos marxistas- deja de lado -quizás intencionalmente- - una de sus facetas más sobresalientes: sus críticas y su rechazo a la violencia como medio para resolver los problemas naciona- les. Y ello porque era consciente -como pocos en su tiempo- de que la violencia, al multiplicarse, se convierte en un "espiral de violencia", del cual los más perjudicados terminan siendo los que no poseen arma alguna para defenderse: los pobres. Por supuesto que era consciente de que una situación de aguda "violencia represiva" podía arrinconar a determinados sectores de la sociedad a optar por la "violencia revolucionaria", la cual en cierto modo se explicaba como resultado de aquélla.

Pero eso no significaba para él aceptar o, peor aún, aplaudir las acciones de las organizaciones político-militares. Incluso al igual que contra la "violencia institucionalizada", la "violencia represiva" y la "violencia terrorista", Monseñor Romero criticó y rechazó tajantemente lo que él llamó "violencia fanática": "esa violencia fanática que casi se hace 'mística' o 'religión' de algunos grupos o individuos. Endiosan la violencia como fuente única de justicia y la propugnan y practican como método para implantar la justicia en el país. Está mentalidad patológica hace imposible detener el espiral de violencia y colabora a la polarización extrema de los grupos humanos"2. ¿Era por eso entonces Monseñor Romero “enemigo" de los grupos guerrilleros? ¿Era por eso entonces partidario de su exclusión como actores para la solución del conflicto sociopolítico que se estaba gestando en el país?

La respuesta a esas interrogantes es no; Monseñor Romero, aunque era consciente del fanatismo al que eran proclives estos grupos - fanatismo que él condenaba-, sabía también de las razones que los habían llevado a su opción violenta y de lo necesaria que era su participación - al igual que la de los militares, los empresarios y los políticos- en la solución de la problemática nacional.

De un encuentro con un miembro de las Fuerzas Populares de Liberación (FPL), Monseñor Romero consignó en su Diario lo siguiente: "otra reunión, ya entrada la noche, fue con un elemento de las FPL, fuerza clandestina, que es muy temida entre nosotros, causa de varios secuestros, pero con los cuales he podido entrar en diálogo con el objeto de expresar el sentimiento y los pensamientos de la Iglesia y hacer comprender que el respeto de estos sentimientos cristianos de la mayoría del pueblo, serán una condición para que ellos pueden

2. La Iglesia y las organizaciones populares. Tercera carta pastoral de Monseñor Oscar A. Romero, Arzobispo de San Salvador y Primera de Monseñor Arturo Rivera Damas, Obispo de Santiago de María, 1978. 


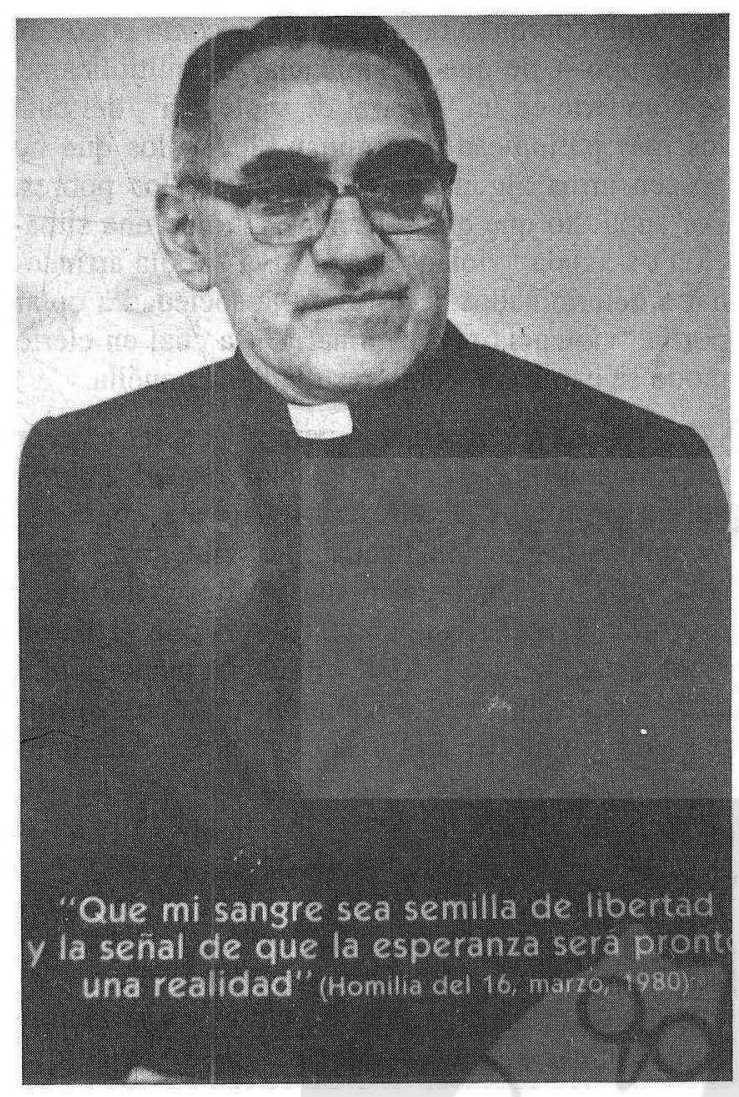

disfrutar de la popularidad de que carecen, cuando atropellan estos sentimientos" ${ }^{\prime 3}$. Duras palabras para los grupos armados de izquierda, dichas en una momento - febrero de 1980 - en el cual Monseñor Romero había sido identificado por los grupos de la extrema derecha — de los cuales salió el comando que lo asesinó un mes después - con la "subversión comunista". Palabras duras, pero no de condena brutal, sino de llamado a la moderación y al realismo, cuya ausencia era notoria en los grupos político-militares.

Por supuesto que los grupos político-militares tuvieron su propia percepción de la figura y obra de Monseñor Romero, al igual que la tuvieron los militares, los empresarios y los políticos. Organi- zaciones como las FPL tenían una postura bastante clara acerca de la posición que debía asumir la izquierda armada ante el "clero progresista": sumarse al proceso revolucionario. Y ello como parte del aporte del cristianismo a la revolución. "Las FPL llevan este pensamiento -se dice en un documento de esta organización-en forma práctica: dondequiera que haya un militante católico que desee dar este salto en su práctica revolucionaria y que llene los requisitos exigidos por nuestra Organización, no tenemos porqué rechazarlo, porqué cerrarle las puertas y realice su aspiración de servir a la causa revolucionaria de su pueblo"4. Pero, obviamente, no se trata de esperar pasivamente a que los católicos se incorporen a la revolución; se tiene que trabajar estratégicamente en ello, pues hay que ganar "para la revolución a un sector fundamental sin el cual ésta no podría triunfar"s, aun al precio de que se crea que "estamos aprovechando el trabajo de otras personas"

En este trabajo de incorporar a la revolución a creyentes católicos, las organizaciones político militares hicieron gala de infinidad de recursos. Una de las vetas que mejor explotaron fue la surgida en las comunidades eclesiales de base, en donde trataban de ubicar a los católicos más despiertos políticamente, para reclutarlos para la organización. También sabían de la importancia de contar con el apoyo de sacerdotes $y$, mejor aún, de figuras eclesiales de rango superior como los obispos. En este último caso la tuvieron difícil no sólo con la mayoría de obispos salvadoreños - francamente conservadores-, sino con Monseñor Romero, cuyo compromiso con el cambio social no excluía fuertes críticas tanto a la violencia de los grupos político-militares como a la forma en que estos irrespetaban los sentimientos religiosos del pueblo. Así, pues, mientras vivió, Monseñor Romero no pudo ser contado por los grupos guerrilleros como uno de los suyos. Era muy crítico y realista para aceptar en su totalidad lo que esos grupos representaban o para que éstos lo admitieran como uno más de sus militantes.

3. Mons. Oscar A. Romero, Su diario, p. 404.

4. Fuerzas Populares de Liberación "Farabundo Martí, “Nuestra actitud ante la religión”. Estrella roja, No. 2, 1975, p. 22.

5. Ibíd., p. 23.

6. Ibid. 
Una vez muerto, las FPL no dudaron en hacerlo uno de los suyos, sabedores de la carga simbólica que ello traía consigo. En un poema anónimo, publicado en El Rebelde - un órgano de propaganda de esta organización - quedó plasmada la visión que este grupo político-militar forjó de Monseñor Romero.

\section{Homenaje a un cristiano heroico ${ }^{7}$}

\section{Compañero Oscar Arnulfo}

después de todo,

haber hecho su Guerra Prolongada

desde una trinchera llamada Iglesia católica,

lo acerca a la doctrina que nosotros

justificamos con otros medios

dentro de la lucha armada.

Su inmenso sacrificio de hombre

y revolucionario

es expresión de una verdad suprema: el poder para el pueblo.

En cada homilía suya

se multiplicaron las conciencias, no así los peces hipocristianos; estos se redujeron en torno a la traición, como modernos Judas del imperio, por un puñado de monedas leyendadas con un refulgente "in God we trust".

De nuestra parte, gracias por no dejar solos a los muertos ni a los vivos;

por no negar a los cristos obreros, a los cristos campesinos, a los cristos organizados, cuando al cantar del gallo revolucioanario, comenzaron a atacar los centuriones con sus $G-3$, sus cruzadas antipopulares, sus delaciones y sus masacres.

Y, "como el color de la sangre ¡Adelante, compañero Oscar!
¡Usted puede decir con orgullo:

"Misión Cumplida, Pueblo!"

¡Aquí seguiremos nosotros con la nuestra!

¿Revolución o muerte!

¡El Pueblo Armado Vencerá!

24 de marzo de 1980

Paradoja de paradojas, mientras la derecha más vociferante se empeñaba en hacer de Monseñor Romero un portavoz de los "grupos marxistas" para atacarlo y, en definitiva, para dictar su sentencia de muerte, agrupaciones como las FPL lo proclamaban uno de los suyos, presuntamente para honrarlo y situarlo en lo más alto del panteón de sus héroes revolucionarios. Los primeros lo acusaban de revolucionario para legitimar su muerte; los segundos, una vez asesinado, lo hacían de los suyos para sumar a sus filas a los cristianos identificados con los sueños y desvelos de Monseñor Romero. Si él era un revolucionario, ellos también lo eran; si la vanguardia de la revolución eran los grupos político-militares, no quedaba más alternativa que apoyarlos activamente.

Vistas las cosas con una mayor distancia, tanto los radicales de derecha como los radicales de izquierda estaban equivocados. La relación de Monseñor Romero con la izquierda armada salvadoreña, en la década de los años setenta e inicios de los años ochenta, no fue simple ni unívoca. La tesis de la identificación de Monseñor Romero con los grupos político-militares, con su praxis e ideología, no tiene sustento alguno en la realidad ${ }^{8}$. Monseñor Romero trató de entender, no de justificar, esa opción revolucionaria; no fue ajeno a sus peores implicaciones - el fanatismo, la absolutización de la organización, el temor que despertaba-, pero estaba claro de que la solución (o agudización) de la problemática nacional tenía que ver con el modo en que esos grupos se fueran perfilando en el escenario sociopolítico del país.

¿Por qué Monseñor Romero pudo situarse como lo hizo en esas difíciles circunstancias sociopolíticas? Desde la teología, la respuesta es que

7. En Fuerzas Populares de Liberación "Farabundo Martí", El Rebelde, No. 88-89, marzo de 1980, p. 27.

8. Tampoco lo tiene la tesis que afirma que Monseñor Romero condenó, sin matiz o consideración alguna, la opción revolucionaria tomada por esos grupos. 
Monseñor Romero fue un hombre privilegiado por Dios para leer los "signos de los tiempos", posicionarse y actuar en concordancia con ellos. Desde una perspectiva más secular, se puede decir que Monseñor Romero pudo hacer lo que hizo, porque fue un hombre a carta cabal, comprometido con los problemas de su país y consciente del rol que le tocaba jugar en las difíciles circunstancias por las que él mismo atravesaba. En otras palabras, fue un hombre honrado con la realidad. Fue un hombre abierto a lo que los demás podían decirle o enseñarle, sobre todo a lo que le podían decir los más pobres de El Salvador. Y en esto radicó lo extraordinario de él: en haber sido un ser humano cabal, un ser humano que con sus debilidades, titubeos, incertidumbres pudo, tras buscar incansablemente los "signos de los tiempos", estar a la altura de las exigencias que planteaba la realidad histórica salvadoreña, responder a lo que el país esperaba de su líder espiritual. La santidad de Monseñor Romero - lo que de extraordinario hubo en él- no excluye su humanidad - con sus debilidades y desaciertos-, sino que más bien la presupone y exige como algo constitutivo. Ignacio Ellacuría llegó a decir que con Monseñor Romero "Dios pasó por El Salvador", pero con el Monseñor Romero humano, hombre, persona de carne y hueso, con debilidades y virtudes.

Ahora que muchos en El Salvador rinden honores a figuras que vivieron para la guerra y para exterminar a otros - por ejemplo, Domingo Monterrosa y Roberto D'Aubuisson- es bueno recordar a quienes vivieron para defender la vida, la paz y la justicia entre los salvadoreños. Monseñor Romero es figura señera en la defensa de esos valores. Monseñor Romero fue un verdadero patriota, a la vez que fue un verdadero cristiano. Como tal merece ser recordado y celebrado por todos los que en El Salvador y en el mundo creen que vale la pena comprometerse en la defensa de la vida, la convivencia pacífica, el respeto a los demás, la tolerancia y la justicia. 